\title{
Reconhecer a diferença: o desafio da etnopsiquiatria
}

\author{
(Acknowledging difference: the challenge of ethno-psychiatry)
}

(Reconocer la diferencia: el reto de la etnopsiquiatría)

\author{
Lucienne Martins Borges* \\ Jean-Bernard Pocreau*
}

\begin{abstract}
Resumo
Reconhecer a diferença do Outro é o fundamento da etnopsiquiatria, que é necessariamente múltipla e portadora de nuances e de diferenças. É com base na prática clínica no Serviço de Auxílio Psicológico Especializado aos Imigrantes e Refugiados - Sapsir, em Quebec, Canadá, que os autores propõem outro olhar sobre essa disciplina, levando em consideração a dimensão cultural e psíquica da pessoa; apoiam-se também sobre os universos existenciais e humanistas como a necessidade de sentido, de continuidade de si mesmo e de coerência, assim como sobre as diversas dimensões da identidade. O dispositivo clínico proposto, de acordo com os princípios da etnopsiquiatria, articula-se em três eixos: trabalho sobre as relações, trabalho sobre as diferentes dimensōes da identidade, trabalho sobre a coerência e o sentido das situações vividas. Essa abordagem permite acompanhar e facilitar as elaborações essenciais implicadas no trabalho psíquico dos refugiados e das pessoas que foram expostas a situações extremas, como a tortura.
\end{abstract}

Palavras-chave: etnopsiquiatria; psicoterapia intercultural; imigração.

\begin{abstract}
acknowledging the Other's difference is the basis of ethno-psychiatry, which is necessarily multiple and bears subtleties and variations. Based on their practice at the Service d'aide psychologique spécialisée aux immigrants et réfugiés - SAPSIR, Quebec/Canada, the authors propose another perspective for this discipline, taking into account the individual's cultural and psychological features, the various dimensions of identity,
\end{abstract}

\footnotetext{
Texto recebido em novembro/2008 e aprovado para publicação em fevereiro/2009.

Artigo publicado em 2006, em francês, na revista Santé Mentale au Quebec, 31 (2), 43-56.

Psicóloga, pós-doutoranda em Psicologia na Unité d’Ethnopsychiatrie et de Stress Post-Traumatique. Université Laval, Quebec, Canadá, e-mail: lucienne.martins-borges@psy.ulaval.ca

** Professeur associe, École de Psychologie, Université Laval, Quebec, Canadá.
} 
as well as existential and humanistic universals such as the self's need for meaning, continuity and coherence. The proposed clinical approach, according to the principles of ethno-psychiatry, is structured around three axes: working on links, working on different dimensions of identity, and working on the coherence and meaning of experienced situations. This approach allows following and facilitating essential elaborations involved in the psychological care to refugees and individuals exposed to extreme situations such as torture.

Keywords: Ethno-psychiatry; Intercultural psychotherapy; Immigration.

\section{Resumen}

El reconocimiento de la diferencia del Otro es la base de la etnopsiquiatría, la cual es necesariamente múltiple y en sí portadora de sutilezas y diferencias. Es a partir de su práctica en el Servicio de Ayuda Psicológica Especializada para los Inmigrantes y Refugiados - SAPSIR, Quebec/Canadá que los autores proponen otra visión acerca de esta disciplina. Se apoyan en los universales esenciales y humanistas, tales como la necesidad de sentido, de continuidad de sí y de coherencia, así como en el sentido de las situaciones vividas. El dispositivo clínico propuesto se articula alrededor de tres ejes: el trabajo en los enlaces, en las diferentes dimensiones de la identidad y en la coherencia y el sentido de las situaciones vividas. Este paso permite acompañar y facilitar las elaboraciones esenciales implicadas en el trabajo psíquico de los refugiados y de las personas que han sido expuestas a situaciones extremas, tales como la tortura.

Palabras clave: Etnopsiquiatría; Psicoterapia Intercultural; Inmigración.

etnopsiquiatria, como abordagem clínica do humano em toda sua

A complexidade, encontra sua plena legitimidade no reconhecimento da diferença do Outro. A etnopsiquiatria considera essa distinção sua questão central, sua pedra angular. Essa constatação fundamental não deve, porém, limitar-se a essa única particularidade, mas também deve ser estendida aos diversos tipos da prática da própria etnopsiquiatria, isto é, reconhecer os diferentes tipos de etnopsiquiatria. Gostaríamos de apresentar algumas pistas de compreensão, de intervenção e de reflexão oriundas de nossa própria prática no Service d'Aide Psychologique Spécialisée aux Immigrants et Réfugiés (Sapsir) ${ }^{1}$. Essa clínica, fundada em 2000, na cidade de Quebec, Canadá, exerce suas atividades no Departamento de Psicologia da Universidade

Serviço de Atendimento Psicológico Especializado aos Imigrantes e Refugiados. 
Laval e constitui uma das áreas de atividade da Unité d'Ethnopsychiatrie et de Stress Post-Traumatique ${ }^{2}$. Desde 2004, o Sapsir é reconhecido pelo Alto Comissariado da ONU para Direitos Humanos como um dos programas canadenses que oferecem atendimento psicológico e psicossocial a vítimas de tortura. Trata-se, efetivamente, de outro olhar possível sobre a etnopsiquiatria, levando em conta a dimensão cultural e psíquica da pessoa, mas apoiando-se igualmente sobre universos existenciais e humanistas, tais como a necessidade de sentido e de coerência, e sobre os impactos psicológicos das dimensões da identidade.

As reflexões suscitadas pelo percurso dos refugiados (a maioria deles expostos a situações extremas no próprio país de origem) não têm, necessariamente, repostas. Porém elas sugerem direçôes e forçam a pensar o sofrimento em novos termos, menos técnicos e teóricos, e de forma mais humanista. Tais questôes existem em qualquer contexto cultural, conforme modalidades e significantes específicos. O sofrimento é universal. Ele faz parte da condição humana, mas sua estruturação, sua expressão, é fundamentalmente cultural, assim como a maneira de reagir ou de compor com ela. Sabe-se que algumas das grandes funções psicológicas da cultura são tornar o real suportável, proteger o indivíduo e o grupo, colocando à sua disposição modalidades de defesa, significações, soluções possíveis de reparação, tornando-se indispensável à sobrevida da pessoa, mesmo podendo contribuir à sua eliminação, caso o equilíbrio do grupo se encontre comprometido.

A tentativa de fugir de sua própria história conduz o refugiado para longe de sua terra natal, com esperança de que esse rompimento radical com os seus será salutar e facilitará seu renascimento. A fantasia de "refazer sua vida em outro lugar", de "recomeçar do zero", não é nem realista nem compatível com o que se conhece sobre o funcionamento humano. A etnopsiquiatria, e em particular os trabalhos de Georges Devereux $(1967,1972)$, de Tobie Nathan (1986, 1994), de Marie-Rose Moro (1988, 2004), citando-se apenas alguns autores, evidenciaram a vulnerabilidade psíquica daqueles que foram forçados ao exílio, que, no país, deixaram seu semelhante, sua "sombra", e, às vezes, sua alma. Perda ou distanciamento das referências fundadoras, do quadro cultural, do "envelope", e ruptura dos laços significativos comprometem o futuro e fragilizam a identidade. A solução esperada transforma-se em complicação. Assim, aos traumas vividos no país, acrescenta-se, muitas vezes, o trauma do exílio, e a migração torna mais complexa a restauração do equilíbrio psíquico, a reparação das desordens e a cicatrização das feridas. O exílio raramente 
leva à cura, mesmo que, às vezes, ele possa representar uma solução salutar e necessária.

Que tipo de psicoterapia deve-se considerar? Qual quadro teórico permite pensar o sofrimento dessas pessoas? Qual dispositivo clínico se deve conceber para que as condições de uma mudança sejam reunidas? A prática aqui exposta inspira-se na etnopsiquiatria, em seus princípios fundamentais. O mal-estar que, às vezes, essa disciplina provoca é, sem dúvida, o reflexo de tensões ideológicas que atravessam o mundo. Além do fato de que a prática da etnopsiquiatria é eminentemente política (Andoche, 2001), falar dessa disciplina supõe, também, e, antes de tudo, uma tomada de posição: a de denunciar a ilusão de que existiria uma única etnopsiquiatria, a que anima a mídia (particularmente a francesa) de debates ardentes. A etnopsiquiatria, como psicoterapia, é necessariamente múltipla, mutável, portadora de nuances e de diferenças, pois seu exercício apoia-se na prática das mestiçagens de universos lógicos, do quadro, das maneiras de pensar o sentido (mais do que a causa) e o tratamento dos transtornos (particularmente no que se refere aos objetivos de intervenção). Ela não é nem uma teoria fechada, etnocêntrica, isto é, à maneira ocidental, nem a aplicação de uma abordagem inteiramente codificada.

Diversidade, portanto, da etnopsiquiatria dita "clínica" é condição necessária e resultado de uma prática aberta à mestiçagem dos seres e das habilidades, mas também unidade, pois o ponto comum é, segundo Devreux $(1967,1972)$, a aplicação de uma metodologia complementarista. Trata-se, segundo o autor, de uma "generalização metodológica" que coordena diferentes teorias e métodos pertinentes ao objeto. As "ciências antropológicas" e as "ciências psicológicas" (mais precisamente uma psicanálise que se interessa pelas relações entre o sujeito e sua filiação e afiliação) são referências complementares, mas não simultâneas, sem, portanto, serem exclusivas. A etnopsiquiatria beneficia-se, hoje, de uma intensa reflexão cujas controvérsias não foram inúteis nem estéreis. Essa disciplina enriqueceu-se de novas práticas e ampliou sua compreensão a respeito do funcionamento humano, quer seja no âmbito normal, quer seja no patológico. A dimensão do sagrado, da alteridade, do encontro do Outro no equilíbrio e no futuro humano é reconsiderado pelo seu legítimo valor e ocupa, doravante, um lugar na prática da etnopsiquiatria.

A etnopsiquiatria é mais do que uma psicoterapia metacultural ou uma socioterapia, mais do que uma técnica de cuidados aplicada ao indivíduo e à sua família, e não se limita à supressão dos sintomas tanto físicos como psíquicos. Ela visa à restauração da vitalidade da pessoa, de todas 
as suas dimensões e de seus diversos canais de expressão. Na sua obra, Anthropologie de la maladie, Laplantine (1986) aborda a questão das relações entre o médico e o religioso, isto é, "da saúde e da salvação". Essa questão fundamental do religioso, e, de forma ainda mais abrangente, da relação com o Sagrado, parece exercer um tipo de coerção lógica sobre a reflexão e a prática da etnopsiquiatria. Se o doente ou seu grupo de afiliação, vítima de transtornos, alia-se, inevitavelmente, ao mundo invisível, ao Além, para encontrar sentido e socorro à sua experiência dolorosa, o psicoterapeuta não pode fugir dessa experiência quase mística. Confrontado aos limites do dizível, do pensável, do imaginável e, em estreito contato com o sofrimento do paciente, como não perceber e sentir essa experiência como da ordem do Sagrado? Tais questões teóricas constituem o âmago da prática da etnopsiquiatria atual, e será apresentado, em seguida, uma de suas modalidades, com base na experiência no Serviço de Atendimento Psicológico Especializado aos Imigrantes e Refugiados (Sapsir).

Antes de tudo, deve ser especificado de que lugar, a partir de que função, de que tipo de atividade e de que população essas observações serão expostas. Isso permite mostrar como o lugar terapêutico ao qual pertencem os profissionais do Sapsir constitui uma pequena comunidade, fundada a partir da expressão de produção humana, tal como a enunciação dos fatos, a narração, a evocação de lembranças (às vezes felizes, mas, mais frequentemente, tristes), a compreensão mútua, as emoções, os afetos, e, é claro, a ativação do sentido e das significações. Uma variedade de laços e de relações é então estabelecida no interior do dispositivo clínico, para que torne possível o projeto terapêutico.

Os profissionais do Sapsir pertencem, de certa forma, ao mundo da Psicologia, aquela dita "clínica e patológica", onde se procura exercer uma forma de etnopsiquiatria com imigrantes, mas, principalmente, com refugiados, aqueles chamados de migrantes involuntários, exilados e que não optaram pela ruptura e pela distância entre eles e suas referências originais, nem mesmo entre eles e seu espaço de vida. Como indicado acima, essa experiência clínica foi adquirida por meio de uma prática regular, quase cotidiana, no Sapsir.

\section{O serviço de atendimento psicológico especializado aos imigrantes e refugiados - SAPSIR}

Em que consiste esse serviço? De forma breve, pode-se dizer que se trata de uma clínica do exílio e da migração, uma clínica do vínculo e da mediação, 
de um espaço transacional, de fala, mas também de ação, onde é exercida uma atividade terapêutica dispensada por uma equipe de psicólogos e doutorandos em Psicologia, geralmente de origem cultural diferente e que falam, no mínimo, sua língua materna e o francês.

\section{a) O dispositivo clínico}

Os profissionais do Sapsir trabalham em grupo (grupo de terapeutas) dentro de um dispositivo específico, no qual uma atenção particular é dada à dimensão cultural do transtorno e de sua expressão sintomática, sem negligenciar, no entanto, a análise dos funcionamentos psíquicos. De fato, como define Claire Mestre,

a prática da etnopsiquiatria apoia-se sobre uma antropologia que reconstrói um contexto social de sofrimento, decodifica representações específicas da doença e do transtorno, analisa sistemas de aliança das relações humanas e considera a cultura como um conjunto rico, coerente e dinâmico de representações, de narraçôes, de metáforas e de símbolos que ajudam os pacientes a refletir sobre a experiência que vivem, proporcionando-lhes, em seguida, meios de modificar essa experiência (2004, p. 190$191)^{3}$.

O Sapsir foi criado após observações que diziam respeito não apenas à pertinência dessa antropologia, mas também devido à codificação cultural presente na organização e na expressão do sofrimento psicológico de um grande número de imigrantes e refugiados que chegavam ao Quebec. Apenas para ilustrar, o Estado de Quebec tem uma população de aproximadamente 7500000 habitantes e acolhe entre 25000 e 30000 imigrantes por ano, de todas as categorias (autônomos, refugiados, etc.). Considerando apenas a cidade de Quebec, onde são realizadas as atividades do Sapsir, 1500 a 2000 imigrantes se instalam anualmente, entre eles, 800 a 900 refugiados, isto é, quase $50 \%$ do número total de imigrantes, vindos principalmente dos países da Europa do Leste, da Colômbia, do Afeganistão, da Ruanda, do Congo, do Burundi e de países limítrofes.

Quando necessário, é possível contar-se com a colaboração de um mediador linguístico e cultural (comumente chamado de "intérprete"), que assegura tanto a tradução da língua como, igualmente, da cultura. É importante, mas não imperativo, favorecer a expressão da experiência vivida e dos afetos na língua materna e consagrar um grande espaço aos dados culturais e às representaçóes

Citação traduzida do francês pelos autores. Todas as citações que se seguem foram igualmente traduzidas pelos autores. 
sociais. As pessoas são encaminhadas ao Sapsir, em geral, pelos profissionais da saúde e dos serviços sociais (postos de saúde, hospitais, clínicas médicas, ONGs, etc.). Quando a pessoa que encaminha o paciente imigrante ao Sapsir é disponível para acompanhá-lo, sua presença, no primeiro encontro, é, não somente desejada, mas sobretudo de grande utilidade. Esse acompanhamento tem por objetivo, quase sempre, tranquilizar o paciente e validar sua confiança em uma situação na qual, uma vez mais, ele deverá expor sua história.

Esses aspectos clínicos ilustram, de forma concreta, como a etnopsiquiatria é uma prática do vínculo, do encontro, da mediação e da mestiçagem. É, precisamente, para que um encontro se torne possível entre universos de pensamentos e de lógicas culturais diferentes, para que seja viável o estabelecimento de uma relação operante que a etnopsiquiatria se apoia em tal dispositivo, que proporciona o estabelecimento de vínculos múltiplos e de caracteres diversos entre os profissionais, entre o paciente e cada profissional assim como com o mediador cultural (o intérprete) que o acompanha. Esse dispositivo constitui igualmente um espaço de vários níveis de mediação: entre duas línguas, dois universos culturais, temporal entre "um antes e um depois", "outro lugar e outra maneira". Trabalho de mediação, igualmente, no plano psicoterápico entre o interior e o exterior do aparelho psíquico, entre o inconsciente e o consciente, entre o que é dito e o que não o é. Nesse quadro terapêutico, o psicoterapeuta assume uma função de "transmissor" entre esses mundos. Não se deve deixar de evocar o movimento intenso da transferência, da contratransferência e da transferência colateral, isto é, entre os próprios terapeutas. Esse encontro de psiquismos conscientes e inconscientes constitui, de certa forma, um trabalho de mestiçagem. Nunca se deixa uma sessão de etnopsiquiatria sem ser o portador da marca do Outro em sua existência e sem ter sido, pelo menos um pouco, transformado por esse encontro.

\section{b) Perfil dos pacientes}

As pessoas que consultam o Sapsir são refugiadas, vítimas de guerras e de perturbações violentas que marcam sua história nacional, familiar e individual. Tais perturbaçõos correspondem à "destruição do universo de referência, afetando o sentido, a temporalidade, o vínculo ao Outro, a iniciativa [...] e abalam tudo que garante a consistência e a lógica interna do homem que se encontra entre os seus semelhantes" (Monroy, 2003, p. 32). Esses refugiados, desenraizados pelos acontecimentos e pelas circunstâncias trágicas de suas vidas, transplantados contra sua vontade em uma terra de exílio, relativamente neutra a seu respeito, trazem consigo a experiência da ruptura, da violação traumática e da extirpação. Esse percurso não acontece sem ter um impacto 
sobre sua saúde mental e seu funcionamento psíquico, e, acrescenta-se a esse processo, o fato de que a perda do quadro cultural familiar provoca nessas pessoas uma "vulnerabilidade psíquica". Assim, aos traumatismos anteriores que os fragilizaram, acrescenta-se um verdadeiro traumatismo do exílio com consequências psicológicas importantes, particularmente a perda da coesão e da continuidade de si.

\section{c) Modelo de intervenção}

O modelo de intervenção do Sapsir, tanto teórico como prático, é mestiço, pragmático. Ele se apoia nos modelos de Devereux $(1967,1972)$ de Nathan (1986, 1994) e de Moro (1998, 2004), ou seja, aqueles da clínica intercultural. A teoria de Devereux não propóe um dispositivo específico para a intervenção clínica. Porém se retém dessa teoria a forma original e determinada de considerar o material cultural como um poderoso "levier thérapeutique" ${ }^{4}$, suscetível de desencadear associações ou novas cadeias de ideias e de ativar processos mentais bloqueados pela perda do quadro cultural e pelos traumatismos pré e pósmigratórios. Compartilha-se com Devereux o postulado da universalidade psíquica, isto é, do funcionamento psíquico, e, com Moro, a constatação de que "se todo homem tende pelo universal, ele tende ao universal através do que é específico à sua cultura de afiliação" (1998, p. 38). De Nathan foi retido o dispositivo de grupo, principalmente pela sua função de "envelope" e de multiplicador da alteridade. A referência às representaçôes culturais, às lógicas e às hipóteses etiológicas tradicionais, aos ritos de iniciação, de filiação e de afiliação, às regras de denominação e de inscrição na descendência familiar, assim como certas prescrições de ação ou de gestos cuja significação é portadora de um sentido para o sujeito são igualmente usadas de forma transitória e complementar a outras modalidades de intervenção. Enfim, certo estilo de interação no qual todas as intervenções dos coterapeutas passam pela mediação do terapeuta principal, o qual as julgará como sendo pertinentes ou não. A formulação dessas intervençôes variará, podendo assumir a forma de questionamento, de observação ou de proposição de compreensão. Esse desvio pela cultura, pela sua cultura, isto é, a forma como ele se refere a ela e dela se apropria, mostra-se particularmente eficaz, pois permite ao paciente a retomada de contato com o que ele traz dentro de si e do novo vínculo com suas origens. Essas técnicas, específicas ao reforço da aliança terapêutica, devem ser manipuladas com prudência e rigor para não confinar o sujeito ou reduzi-lo somente à sua afiliação cultural ou, pior, à sua origem. Da clínica intercultural

\footnotetext{
Termo que pode ser traduzido por "instrumento terapêutico".
} 
foi mantido seu realismo pragmático e sua preocupação em articular o social e o cultural ao apoiar soluçôes que facilitam a integração à sociedade de acolhimento, sempre atento ao fato de que o intercultural não leva à mestiçagem e que ele não se limita a ajustes de habilidades e comportamentos.

Acrescenta-se que o modelo da etnopsiquiatria, adaptado pelo Sapsir, apoia-se sobre o que caracteriza uma dimensão importante do funcionamento psíquico e também da cultura, isto é, a dinâmica de coerência. Se a cultura torna coerente o espaço social, por sua vez, a necessidade de dar um sentido, de encontrar uma significação a determinada experiência torna coerente o espaço interior. Essa coerência estende-se, igualmente, ao espaço existencial e ao da identidade. A intervenção psicoterápica procura restaurar a capacidade de tornar coerente o que ficou caótico ou fragmentado. Essa integração não se faz de forma aleatória. Trata-se de uma síntese própria ao modelo do Sapsir, caracterizado pela sua dimensão existencial-humanista. Ela decorre da realidade dos pacientes do Sapsir e da experiência clínica que foi possível adquirir e aprofundar com eles.

Essa apresentação teórica permite introduzir as questões fundamentais que se referem a cada pessoa refugiada e que constitui o trabalho psíquico constante que ela deve realizar:

- Como preservar este equilíbrio dinâmico quando viver em outra cultura significa perder o quadro externo, ao menos temporariamente, antes que o novo quadro seja interiorizado?

- Como reaprender a existir ou, mais precisamente, como dar continuidade à sua existência, permanecendo em si mesmo, em uma continuidade psíquica coerente, em outro lugar e em outro momento?

- Como restaurar o narcisismo fundamental, danificado pelas experiências negativas anteriores e pelas múltiplas perdas?

- Como preservar sua identidade quando a pessoa é exposta a uma aculturação brutal, um tipo de "morte cultural", com todos os lutos inerentes a essa realidade?

- Como deixar aberta essa identidade para que as novas experiências possam ser integradas?

Deve ser ressaltado aqui que a vida da pessoa transplantada não se limita ao passado e não se deve fixar, se possível e viável, nas perdas dolorosas experimentadas. Para que a pessoa prossiga, para que a catástrofe e os sofrimentos causados por ela sejam superados ou, pelo menos suportáveis, é necessário que essa pessoa possa abrir-se ao novo espaço de vida, à sociedade de acolhimento e 
construir vínculos significativos com o meio social, por meio do trabalho, da rede de relações sociais (vida associativa laica ou religiosa), da permanência dos contatos com os compatriotas.

A experiência psicoterápica, e em particular a prática clínica com refugiados, inspirada na etnopsiquiatria, conduz também a enfatizar a importância das disposições psicológicas e das atitudes humanas fundamentais dos profissionais, particularmente aquelas que se referem ao acolhimento e à disponibilidade ao encontro com o Outro, e a privilegiar três grandes modalidades técnicas de intervenção sem negligenciar, portanto, as competências gerais de toda psicoterapia. Trata-se, de fato, de acompanhar e facilitar as elaboraçóes essenciais implicadas no trabalho psíquico do imigrante, ou seja:

- as que se referem às perdas e separações: trabalho sobre os vínculos de origem, vínculos de afiliação e vínculos atuais;

- as que se referem à identidade: trabalho sobre as dimensóes da identidade relacionada com a alteridade;

- as que se referem à projeção de si mesmo, no tempo e no espaço: trabalho sobre a coerência e o sentido das experiências passadas e atuais.

\section{Trabalho sobre os vínculos de afiliação e os vínculos atuais}

Trabalhar sobre os vínculos consiste em acompanhar o sujeito na evocação de sua história pessoal, a de sua família, de seus ancestrais. A narração permite, igualmente, reintroduzir o tempo. Consiste em ajudá-lo a reinscrever-se nessa história após a fratura à qual ela foi submetida. Testemunha dessa etapa, a pessoa deve reapropriar-se dela, assumir os lados sombrios, tumultuosos e conflituosos que ela comporta. Assim, ela poderá atingir o status de sujeito ativo e contribuir a escrever e viver novamente sua história. No Sapsir, foram obtidos excelentes resultados ao utilizar-se, de forma livre e espontânea, o genograma, árvore genealógica subjetiva, segundo Moro (2004), a "árvore da vida", pensada pelo sujeito, tanto real quanto fantasiada. Esse genograma trata-se de um poderoso ativador de relaçôes, potencializando as capacidades psíquicas de evocação e capaz de estabelecer ligações. Ele permite, igualmente, ao paciente, afiliar-se às suas origens e reencontrar certa continuidade existencial. O uso de fotos pessoais (fotos de família, do país, etc.), que marcam os momentos significativos de sua vida, constitui também um excelente meio para atingir esses objetivos. Restaurar a capacidade relacional também é, no presente (e na consulta do Sapsir, no "aqui e agora"), reforçar e apoiar os novos vínculos que o sujeito estabelecerá na sociedade de acolhimento. 


\section{Trabalho sobre a identidade e a alteridade}

Falar de identidade requer, em primeiro lugar, que algumas precisões sejam feitas, pois essa noção é bastante sujeita a polêmicas. De antemão, afirmase que ela não deve ser assimilada sem ser colocada em relação estreita com a alteridade. Segundo Moro (2004), a identidade pressupõe a alteridade, "o outro é nomeado e assimilado como um outro eu-mesmo. A identidade não é apreendida como uma substância ou como um estado, mas como um processo, como uma construção dinâmica a ser renovada constantemente na relação ao Outro" (Moro, 2004, p. 12). Trabalhar a identidade como dimensão operatória parece-nos fundamental nesse contexto psicoterápico. $\mathrm{O}$ movimento de identificação é testado de forma rude no percurso migratório no qual tudo, neste âmbito, está por ser reconstruído. O exílio desnuda, o olhar do Outro não é mais o que era. Os vizinhos, o patrão, os colegas de trabalho não mais o reconhecem. $\mathrm{O}$ imigrante deve reinventar-se, recriar-se para os outros. A vulnerabilidade do narcisismo, já ferido pelas múltiplas perdas, aumenta por causa dessa humilhação social. Doravante ele é minoritário e vive como inferior dentro da comunidade de acolhimento. A cultura de origem, portanto fundadora, é a base da humanidade da pessoa, pela língua na qual se constroem seu pensamento e seus primeiros vínculos. Porém não se trata de confiná-lo em sua cultura de origem, em uma concepção do tempo centrada sobre o passado. O que importa é ter como ponto de partida esses dados, esse âmago da identidade, coração da vitalidade e da segurança.

Insistimos em dizer que a referência à identidade é, antes de tudo, uma referência à Pessoa, preocupada com sua identidade, com sua continuidade e com sua similitude consigo mesma, com sua singularidade. Continuidade, estabilidade da autoimagem, coerência do conjunto de representaçôes de si e do Universo, sendo elas, segundo Erickson (1968), as diferentes dimensões implicadas na identidade.

\section{O trabalho sobre a coerência e o sentido}

Dar um sentido ao nosso meio, em seguida a nossas experiências e, enfim, a nossa vida, é tão fundamental e espontâneo quanto o princípio de prazer tal que enunciado por Freud. Viktor Frankl (1970) apreendeu com clareza esse princípio e consagrou a ele uma grande parte de suas atividades clínicas e de pesquisa. O ser humano é produtor de sentido e ele não pode se subtrair dessa pressão do aparelho psíquico. Ele é estimulado pelo que Frankl (1970) chama de "vontade de sentido", que pode ser compreendido como uma pressão interna para dar uma significação a sua experiência. Conforme Frankl (1970), 
o homem pode dar um sentido a seu sofrimento, colher algo de positivo, mesmo nas situações mais dramáticas. Produzir sentido é essencialmente uma experiência de coerência consigo mesmo e com o mundo externo. Significa criar vínculos, estabelecer relações entre as diversas dimensões do ser. $\mathrm{O}$ cumprimento dessa necessidade de sentido se expressa por uma redução da distância entre a experiência interna e os estímulos externos ou as informaçôes da situação vivida. Essa redução do desvio se manifesta nos planos emocional, cognitivo e existencial e deixa o sujeito com um sentimento de harmonia interior e de coerência. Détraux (2003) coloca também em evidência a relação entre esse conceito e o de resiliência.

A pessoa refugiada, assim como aquela que foi exposta a situações extremas (agressão sexual, violências, etc.), não resiste a essa necessidade de encontrar um sentido, mas essa função semiótica encontra-se, muitas vezes, muito comprometida pela severidade dos eventos vividos. É possível então, em muitos casos, falar-se de traumatismo do non-sens e da incoerência. Esses traumatismos específicos são particularmente devastadores, e os sintomas associados traduzem as rupturas da organização interna, a perda da harmonia psíquica (clivagem, desorganização, perdas das referências, perturbação do mundo dos valores, etc.). Assim, como é possível restituir ao paciente uma possibilidade de sentido a situações tão incompreensíveis? Essa atividade de restituição de sentido para o sujeito é um trabalho que requer paciência, é um trabalho progressivo que só se torna possível no fim do percurso terapêutico. Ela é o ponto culminante. Assim é mais fácil, pois mais acessível, de coconstruir com o paciente um sentido a situações atuais. Ressalta-se, enfim, a importância da coerência do projeto de vida que a pessoa pode vir a elaborar. Esse deve respeitar o que a pessoa atual é, o que ela se tornou, mas também o que ela foi e o que ela poderia ser. É a partir dessa coerência interna e existencial, dessa unidade, que a continuidade psíquica de si poderá ser restabelecida.

Deve-se sublinhar, enfim, a importância da reparação, para que a recuperação seja completa e durável. Evidentemente, a reparação necessita o reconhecimento por parte do Outro ou do grupo social dos sofrimentos infligidos (psíquicos e outros), da injúria feita a um dos seus. A dinâmica pessoal da vítima se modifica e o impacto patogênico da injustiça pode, então, evoluir. $\mathrm{O}$ ressentimento e a atitude reivindicadora, tão frequentemente observados como expressão do sofrimento, tendem, nessas condições, a apaziguar-se. A reparação assim entendida abrirá, eventualmente, a porta a outra disposição psicológica: a do perdão.

A etnospiquiatria, em algumas de suas modalidades práticas, sobretudo como clínica do vínculo e do encontro, do sentido e da mediação, e, mais 
particularmente, como experiência de coerência, propõe algumas soluções aos desafios representados por esses desastres existenciais. Apoiando-se sobre as diversas dimensões dinâmicas da identidade e da alteridade, sobre os impactos mobilizadores das relaçôes com o outro e com o grupo social, essa abordagem torna possível também uma melhor compreensão da forma como os traumatismos são metabolizados e transformados quando a pessoa pode se reapropriar de sua história, a sua e a de sua família, de seus filhos e de seu grupo, de sua afiliação.

\section{Referências}

Andoche, J. (2001). Culture et santé mentale: les avatars français de l'ethnopsychiatrie. In: Dozon, J.-P. \& Fassin, D. (org.). Critique de la santé publique. (p. 281-308). Paris: Baland.

Détraux, J.-J. (2003). Annonce de la déficience de l'enfant aux parents: facteurs favorisant un processus de résilience et l'émergence d'un sentiment de cohérence. In: Le Cardinal, G. (org.). Du désastre au désir. Les modalités de l'accompagnement post-traumatique. (p. 37-53). Paris: L'Harmattan.

Devereux, G. (1967). Le renoncement à l'identité comme défense contre l'anéantissement. Revue Française de Psychanalyse, 31 (1), 101-142.

Devereux, G. (1972). Ethnopsychanalyse complémentariste. Paris: Flammarion.

Erikson, E. (1968). Identity, youth and crisis. London: Faber and Faber.

Frankl, V. (1970). La psychothérapie et son image de l'homme. Paris: Éditions Resma.

Freud, S. (1968). Au-délà du príncipe du plaisir. In: Freud, S. Essais de psychanalyse. (p. 7-82). Paris: Éditions Payot. (Originalmente publicado em 1920).

Laplantine, F. (1986). Anthropologie de la maladie. Paris: Payot.

Mestre, C. (2004). La psychiatrie transculturelle: un champ nécessaire et complexe. In: Moro, M.-R. et al. (org.). Manuel de psychiatrie transculturelle. Travail clinique, travail social. (p. 179-195). Grenoble: La Pensée Sauvage, 
Grenoble.

Monroy, M. (2003). La fragile consistance de "l'être-là". In: Le Cardinal, G. (org.). Du désastre au désir. Les modalités de l'accompagnement post-traumatique. (p. 31-36). Paris: L'Harmattan.

Moro, M. R. (1998). Psychothérapie transculturelle de l'enfant et de l'adolescent. Paris: Dunod.

Moro, M.-R; De La Noe \& Mouchenik, Y. Q. (2004). Manuel de psychiatrie transculturelle. Travail clinique, travail social. Grenoble: La Pensée Sauvage.

Nathan, T. (1986). La folie des autres. Traité d'ethnopsychiatrie clinique. Paris: Dunod.

Nathan, T. (1994). L’influence qui guérit. Paris: Éditions Odile Jacob. 